of the leukaemic symptoms was ever brought about. At the post-mortem examination excess of lymphocytes was found in several organs, and the blood throughout retained its leukaemic aspect as far as the differential count was concerned. At the same time the patient undoubtedly improved enormously coincident with the fall in total number of his white cells, and it was not till the septic infection alluded to had set in that his progress towards apparent recovery was interrupted.

\section{CASE IIT.-Lympho-sarcoma.}

P. G., aged 65, a farmer, was admitted on May 11th, complaining of lumps in his neck and of difficulty in breathing and swallowing. He stated that he had always been a healthy man until about seven months previously. He then noticed a swelling on the right side of his neck, and shortly afterwards found that his breathing at night was troublesome so that he had to sit up in a chair. He also began to be troubled with a cough, without expectoration, and by hoarseness, and before admission to hospital coughed incessantly day and night. Early in April he found difficulty in swallowing, and could only get down fluids.

On admission enlarged glands were found on both sides of his neck. On the right side these were very big, and practically filled up the cutire space between the clavicle and the lower jaw ; on the left side they were smaller. The veins on both sides were distended. In the thorax there was an area of dullness over the manubrium sterni, and extending slightly out on each side beyond the sternal margin. This dull area merged below with the cardiac dullness. The breathing was slightly stridulous, and on auscultation seemed very harsh all over the upper part of the thorax. An $x$-ray examination crer the un showed that the rays presumably due to the presence of a growth, and also showed an area of opacity extending on each side of the heart. In the abdomen nothing abnormal was found except slight splenic enlargement. The glands in the groins and axillae were
palpable, and perhaps very slightly enlarged. Laryngeal palpable, and perhaps very slightly enlarged. Laryngeal right vocal cord.

ight vocal cord.

The blood examination was as follows : Red cells, 3,210,000 white cells, 11,660; haemoglobin, 65 per cent. Differential count : Neutrophiles, 61 per cent.; lymphocytes, 31 per cent. ; hyaline cells, 7 per cent. ; eosinophiles, 1 per cent. Wassermann test negative.

The diagnosis made in this case was lympho-sarcoma. Not anticipating a favourable result, I did not have one of the neck glands removed for section. In consequence the diagnosis must remain open to doubt; but the picture of an intrathoracic grovth, with enlarged glands in the neck and slight splenic growth, enlargement, appears to me practically unmistakable, and in my own mind I have no doubt that the diagnosis was correct: disease.

On May 13th benzol was started, and 60 minims were given daily up to June 2 nd. The dose was then increased to 90 minims daily, and this was continued until July 3rd, when the drug was discontinued. An $x$-ray exposure was given every third day rom May 13th to July 13th.

During the first three weeks in hospital the patient complained much of his breathing and of his cough, and felt a sensation of choking immediateiv on lying down. It was necessary to give morphine each night to give him relief. After the lapse of three weeks the glands in the neck were much smaller than on admission, and after a month they had completely Cisappeared. The dullness over the upper part of the thorax began to diminish, and a series of $x$-ray photographs seemed to indicate a gradual clearing of the intrathoracic opacity.

Symptoms also improved and by the middle of June the patient was quite free of cough, of hoarseness, and of difficulty patient was quit

On June 20th Dr. Graham again examined his larynx, and On June 20th Dr. Graham again examined his larynx, and
could then find nothing abnormal. On July 3rd a purpuric could then find nothing abnormal. On July 3rd a purpuric there urticarial wheals. 'This was regarded as a sign that the there urticarial wheals. 'This was regarded as a sign that the
benzol had been pushed far enough; it was therefore discontinued and the skin eruption rapidly cleared up. The patient left hospital on July 16th feeling and looking perfectls well.

A comparison of radiograms taken on May 13th and on July 15th, and now exhibited, I think, leaves no doubt that the thoracic opacity had largely cleared up. Some opacity undoubtedly remains in the latter $x$ rar, but this could only be expected, as some fibrous change would probably accompany the disappearance of a lympho-sarcomatous growth.

During the course of the benzol treatment the white cells sank from 11,660 on admission to 4,000 per c.mm., but increased later to 6,000 per c.mm.; no change took place in the differential count, the red cells increased from $3,210,000$ to $4,300,000$, and the haemoglobin from 65 per cent. to 75 per cent.

In recording this case as a cured case of lympho. sarcoma the following queries arise, namely: (1) Was the diagnosis correct? This question has already been dealt with. (2) Is the cure permanent? The answer to this lies, of course, in the future. The patient promised to conmunicate with me at once if any symptoms returned, and so far I have not heard from him. (3) Was the benzol or the $x$-ray treatment the factor in bringing about the improvement? This question, of course, cannot be answered. My own previous experience of $x$-ray treat. ment in both Hodgkin's disease and lympho-sarcoma is uniformly unfavourable.

I am therefore inclined to think that the benzol was the more important factor. The case seemed so serious on admission that I did not feel justified in employing benzol alone, as I felt that in so formidable a disease everything that could pis ibly be of value should be at once put in action.

Case IV:-Osteo-sarcoma.

Encouraged by the result obtained in Case III, a course of benzol was given to a man sent me by $\mathbf{M r}$. Moore, with the s:atement that he was suffering from an inoperable osteosarcoma of the pelvis. The growth had spread in to the groins and was rapidly advancing. The benzol was pushed over a period of four weeks, but no improvement was noted, and in consequence no further details of the case need be recorded.

In conclusion, I have contented myself with reporting these results without speculating on the way in which they are brought about. It appears to me probable, however, that the etiology of the disease may before long be solved through the therapeutic channel now opened out.

\section{TRENCH “FROST-BITE."}

Some Observations on Cases Admitted to the DUChess of Westmingter's WAR Hospital,

BY

C. GORDON WATSON, F.R.C.S., Major R.A.M.C., Commandant, AND

CHARLES S. MYERS, M.D. Captain R.A.M.C., Registrar.

EarLY in December last a number of men suffering from "frost-bitten" feet were admitted into the Duchess of Westminster's Hospital at Le Touquet, usually after a few days in a clearing hospital, and other cases have been admitted since. The following observations, talsen from an analysis of these cases, seem to us worthy of record.

History of Onset.

Such a case as this may be regarded as typical :

CASE I.

Sergeant W. N. marched eight miles to the trenches, which he entered with wet feet. The trenches were very rain fell at first, frost occurred on the second, and snow fell on the third day. He.woke on the third morning in the trenches to find his feet "stone cold" and numb. His feet continued numb although he walked about. He felt pain in them for the first time two days later, on marching to his billet six miles away, which he reached with great difficulty. There he took off his boots, changed his socks, and rubbed his feet, but did not wash them. He slept that night without pain, but the next morning his feet were so swollen that he could not get his boots on. He "reported sick." The feet began to be again painful on. He "reported sick." The feet began

"Exposure to cold and wet" would be a more suitable name to apply to these cases than "frost-bite," for in some instances the feet were affected in the absence of actual frost. There were a few instances, too, in which the feet only began to show signs of being affected some days after the patient had left the trenches.

In the slighter cases, especially when the patient left the trenches after only two or three days' exposure, no swelling of the feet occurred, but only numbness followed by pain. In one of the severer cases, on the other hand, the swelling was said to have burst the bootlaces. In several instances the patient managed to remain on duty by wearing larger-sized boots.

The pain before admission was varionsly described as "burning," "throbbing," "like pins and needles," "like electricity." In two cases it was attributed to the "boots getting tight" and compared to "a tight string running up between the laces and across the ankle." Generally, the pains increased as the swelling diminished, when the shooting pains, described below, usually began. In a few cases, however, the pains in the toes were preceded by "cramps" in the legs and pains in the knees.

At this stage, when the boots were removed before or at the onset of swelling, the feet were found to be not only 
Sometimes the swelling and pain were not preceded by any noticeable numbness. When present the numbness was usually confined to the feet, but occasionally extended up the legs.

The percentage frequencies of the occurrence of numbness, swelling, and pain were $34,68,82$ respectively. In by far the majority of cases this was also the time-order of their appearance.

Some of the patients had been instructed by their officers to warm their numbed feet at the fire or to wash them with warm water; others had been warned to avoid warmtli, or had been told to rub their feet with oil or grease. Such initial treatment did not seem appreciably to affect the subsequent severity or course of the symptoms.

Condition on Admission.

Many of the patients were suffering from the effects of general fatigue and insomnia.

At the time of their admission the swelling in their feet of which the patients had complained had in most cases disappeared. But this was not always so; and in one case not only were both feet swollen and tender on admission, but the swelling extended up to the middle of the calf. The feet were at this period generally normal as regards temperature; they were often flushed, especially at the toes and still more often sweating freely.

In a few cases, especially where the feet were still cold, discoloration was still present, the toes most frequently being cyanosed. In one case both feet showed a purple mottling, which extended up to the knees. In a small number of cases (4 per cent.) haemorrhage had occurred, usually beneath the nail of the hallax. In a few instances the toes presented a polished appearance. Desquamation was common.

In the great majority ( 89 per cent.) of cases the skin surface was unbroken; these constitute what we shall term" the "first degree" group. In the remainder (11 per cent.) blisters had appeared on the skin, which had usually (in 82 per cent. of these cases) broken before admission, and in some instances had given rise to a definite ulcer. The cases ( 9 per cent of the whole) in which the surface of the epidermis was thus interrupted we shall term the "second degree" group. Still rarer ( 2 per cent.) is the "third degree" group, in which the deeper dermal tissues were in volved; these cases showed all the appearance of dry gangrene. In one of them the necrosed part of the hallux was bounded by a swollen red area and by a bleb containing pris, from which Staphylo. coccus albus was cultivated. (For a more detailed description of these severer cases see Cases $x$ to $x v$ at the end.)

Mobility.-Often the toes, and sometimes the ankles, were stiff, and their mobility was much diminished or absent. The toes were occasionally in a condition of hyperextension. Eren in the slighter cases movements of the foot could often only be carried out with pain and difficulty. Walking had become so painful that in many cases this had been the cause" of the patient "reporting sick.".

Reflexes.-The knee-jerk, when examined, was found to be normal, save in one case, in which the legs were held very stiffly in the position of talipes equino-varus; in this instance an unusually brisk reflex was observed.

Sensibility.-In the majority of the cases there was either definite anzesthesia (65 per cent.), or numbness aecompanied (15 per cent.) or unaccompanied (11 per cent.) by some diminution in sensibility. Thus only in 9 per cent. was there an absence of numbness or lessened sensibility. Hyperaesthesia was recorded in 15 per cent. of all the cases, very rarely without anaesthesia elsewhere. In one case the hyperaesthesia disappeared with increasing pressure of the fingers on the foot.

The plantar surface of the hallux was the seat of the most extensive and severe disturbance of sensibility. Lëss commonly its dorsal surface waś also involved, and still less commonly the plantar and dorsal surfaces of the other toes. In a few cases the whole foot was anaesthetic, and in two cases the anaesthesia extended up the leg.

There seemed to be no constant relation between the disturbances of sensibility and the other symptoms observed. in one case bath foet showed areas of Iiyperaesthesia, but the right foot was hotter and showed a severer anaesthesia. In another case both feet were equally

anaesthetic, but the right foot sweated morc and was more painful than the left. In two cases the warmer foot alonc showed-hyperaesthesia. In one case only the toes wer. swollen, numb, and cold, but were not detinitely anaes. thetic. In two of the three cases of the "third degree" no anresthesia was found outside tlie gangrenous patch; in a case of the "first degree" it was most marked over" the areas of discoloration.

Sensibility ("epicritic") to light touch" (cotton-wool), and the discrimination of double touches (compass points) and of differences of temperaturo (warm and cool tubes). appeared to be lost or diminished together. Sensibility ("protopathic") to painful (needle prick) stimuli-no investigations were systematically carried out with very hot and cold stimuli-was usually the last to be lost, and the first to return during recovery. On its return pain was found to be badly localized, having a radiating cliaracter; by one patient a prick was described at this stage as "ticklish," by another as "scratchy," "shooting," "as if you "were rubbing it with your nail." Frequently before a prick could be recognized as such, it produced in the pavient the illnsion that he was being touched by the tinger or a pencil.

The area of anaesthesia was rarely (the exceptions, 6 per cent., being all, save one, slight cases) confined to oue foot, though one foot often suffered more than the othcr. Thus in one case the condition was as follows:

$$
\text { Right Hallux. }
$$

Prick at first lost, later de-

Prick at "ticklish",

Light touch at first lost, later

present save at tip and over plantar surface of terminal phalanx.

\section{Right Foot.}

Discrimination of temperature differences absent.

Spatial threshold (compass test) more than $30 \mathrm{~mm}$. over middle toe.

As a rule sensibility returued first over the proximal and later over the distal phalanges of the toes.

Several patients complained of alternating temperature (subjective) of their feet-for example, "they feel hot and cold alternately," "they feel cold by day and hot at night," "they shoot in the day, but are cold at night."

As a rule, the pain was greatest or occurred only at night; very often it prevented the patient from sleeping. In the severer cases the early throbbing or burning pain gave place to pains of a shooting character, and no longer remained localized, as before and as in the slighter cases, in the hallux or toes or balls of the feet; it now " run ap the legs" to the knees or even (in 2 per cent. of the cases) to the hips. One patient referred the pain produced by squeezing the toes of his foot to his knee.

Body Temperature.-Only in the severer cases--especially in those in which the foot was. blistered, flushed, or sweating, and the mobility of the toes was lost or much diminished - the temperature rose slightly (to about $99^{\circ}$ F.) at night.

\section{Treatment and Progress.}

Most of the patients remained in this hospital only for a week or ten days, before being sent to England or tho base; consequently little can be said under this heacl. The pain and insomnia were generally relieved by acetylsalicylic acid. Cases of the "first degree" were treater by gentle massage, or by belladonna or camplior liniment or (to relieve the liyperaesthesia) by 1 in 40 carbolic acid compresses. Some underwent no local treatment. In cases of the "second degree" fomentations were applied, followed later by gauze dressing. Picric acid in solution was employed in two cases of the "third degree."

It is hence impossible to compare the efficiency of these different modes of treatment. All that can be said is that every case-even the gangrenous cases-made remarkably good progress. The patients left this hospital, walkino better than when they entered it; though a few were stil unable to walk on their discharge. In several cases a return of the swelling of the feet was noticeable when first the patients began to walk, and at this stage thero was a general complaint of pain, mainly, or only, when they began to put their weight on their feet. 'The pain was usually over the balls of the toes; such patients 
consequently hobbled on their heels. Sometimes the pain in walling was felt in the ankles and legs.

Only the very slight cascs recovered sensibility here completely. Even in cases of only moderate severity progress was in this respect surprisingly slow, considerable areas of anaesthesia remaining after a fortnight's rest. A characteristic feature of the anaesthesia was its variation from day to day, sometimes diminishing, sometimes increasing in extent and severity.

\section{Unusual Cases.}

The foilowing instances of complications and of devia. tions from the normal course hitherto described may conceivably help to elucidate the nature of the affection.

Attention has already been drawn to one case whicl showed a purple mottling of the feet extending to the knees. Another case presented the following history and condition :

\section{Case II.}

Captain R. C. ( . On December 5th (six days before admission here), after several cold, wet days in the trenches, he found his legs numb, cold, and useless. Presently they became painful up legs numb, cold, and useless. Presently they became painful up
to the hips, especially at the knees. There was some stiffiness to the hips, especially at the knees. There was some stifiness legs were stiff and tender, especially in the region of the knees and above them. Over the inner aspects of both knees, but rather below the level of the joint, were large areas of yellow bruising, not traceable to any definite injury, unless to kneeling in cold water for three hours during a four hours' spell. The soles of his feet felt "like lumps of raw beef." There was much teuderness along their outer margins, and also over the dorsum of both feet. The left foot was the more tender. Drawing sock over the left toes evoked a yell of discomfort. Light tonch could be felt on the plantar surfaces of the feet; but he imagined a plantar prick, distal to the centres of the metatarsals, to be the touch of a finger. On both halluces a prick was recognized over the dorsal surface of the distal phalanx, but over that of the proximal phalanx it was called a scratch and third left toes a prick was not felt at all, in the case of the fourth left toe it was called a touch, and on the fifth left toe "certainly not a prick."

In the following cases, also, other regions were affected in addition to the feet:

\section{Case III.}

Private S. M. On November 20th (fourteen dars before admission here), after having been three days in the trenches, the patient felt his feet to be "dead." On walking back to rest, his ankles ached and his right knee also. His ankles swelled, but were not red. The next day his toes became slightly discoloured, but after two days the discoloration disappeared.

CASE IV.

Private H. B. On November 24th (ten days before admission here), he noticed on coming out of the trenches that his toes were discoloured. For a week previously he had had aching pains in both knees and ankles. On November 27 th he had pain in and swelling of the right elbow. On admission he complained of pain over the tubercle of the right tibis and internal condyle of pain over the tubercle of the right tibia and internal condyle of the right femur, and a slight swelling, without redness, was
here noticeable. Over the olecranon of the right elbow there was slight pain, but no swelling. On both feet (which were of normal appearance and temperature) anaesthesia was present over the first three toes and the ball of the hallux, and hyperaesthesia over the fourth and fifth toes and instep.

Case v.

Private F. W. was admitted to clearing hospital on November 30th, and to this hospital on December 4th. On December 7th, in addition to extensive anaesthesia of both feet, the two terminal phalanges of the middle, ring, and little fingers were found to be "numbed."

\section{CASE vi.}

Private J. E., on November 25 th (nine days before admission here), while in the trenches found his feet were swollen. He remained three more days in the trenches and when he came out he was unable to walk. He first noticed that his fingers were tingling on his journey in the train to this hospital. On admission he complained of his fingers "feeling twice as large as usual"; no anaesthesia, swelling or other abnormal as usual "; no anaesthesia,

The difficulty of movement of the toes and occasionally at the ankle-joints in many cases has been already mentioned. In the following two patients, admitted at the same time, difficulty of movement without "frost-bite" was also present.

CASE VII.

Private E. W., fourteen days after admission here began to have pains in his ankles, later in his knees and back. On admission his heart and temperature were found normal. The movements of the legs were carried oit with great caution and with great rigidity. He complained two dass later of shooting pains in the legs.
Case viII.

Private A. G., nine days before admission here began to complain of cramping pains in the back and legs. On admission his heart and temperature were found normat. There was much stiffness of the back and lower lis , 9 , the pains being rague, widely spread, and apparently muscular.

The cultivation of Staphylococcus albus from a bleb at the margin of the area of necrosis in a case of the "third degree" lias been already mentioned. Beside this case may be placed the following:

\section{CASE IX.}

Private J. N. In the trenches between November 12th and 19th, 22nd and 25th, and November 28th to December 1st. Boots not removed between November 22nd and December 1st. Feet continually wet. No swelling of the feet. Since Novem29th, when "stamping" feet in order to get warm, his legs gave way at the knees, and he fell to the ground. On December lst he walked to hospital, a distance of 1,000 yards, in one hour he rwalked to hospital, a distance of 1,000 yards, in one hour
and three-quarters. He had never warmed his feet. On and three-quarters. He had never warmed his feet. On and of normal colour. He complained of a "numbish ache" and of normal colour. He complained of a " numbish ache" movement of the toes. was much diminished. Sensibility to light touch was lost on the dorsal and plantar surfaces of both halluces and on the two next toes of the left foot. Sensibility to prick was lost on both surfaces of the left hallux. The loss extended in each case to the metatarso-phalangeal joint. The remaining toes showed dimiuished sensibility to light touch and prick. He complained of giddiness and falling when getting on his legs during the first three days after admission. Heart and temperature normal; some flatulence.

December 13th. Patient much improved; now getting up. phis morning he noticed a sore on the riged; now getting up. was found a pustule, $\frac{1}{4}$ in. in diameter, surrounded by a dusky blue and a wider oedematous area. It resembled so closely the pustule of anthrax that a bacteriological examination was immediately made. There was no glandular tenderness, and there were no constitutional symptoms. The patient had not received a kick, nor had he been exposed to any obvious source received a kick, nor had he been exposed to any obvious source of contagion. The inflammation disappeared in the course of a
few days. A film of the exudate from the pustule showed no few days. A film of the exudate from the pustule showed no cytes and epithelial cells. A culture of the exudate on agalagar grew a white staphylococcus.

\section{Pathology.}

Frost-bite attacks especially those parts of the body which are most exposed to the air ; it occurs in extremely cold, "arctic," weather. But in the cases here considered the patients had not been exposed to cold of very great severity; and the regions chiefly affected are those which had been most exposed, not to cold only, but to continua? wet and cold.

As in ordinary frost-bite, so in these cases the lesion is no doubt primarily vascular, but it is less severe, more " chronic," in character. Accordingly, actual gangrene is extremely rare, but the nervous, and perhaps the circulatory, disturbances are of longer duration.

It may be supposed that when an area of the body is exposed for some days to wet and cold the numbness which is felt is due to constriction of the arterioles of the region. At this stage a complete and rapid recovery ensues when the part is removed from its previous environ. ment, especially if it be subjected to gentle massage.

Further exposure to wet and cold must upset the normal equilibrium botween the capillary walls and the blood. Extravasation and mottling or discoloration, with some oedema of the skin, will occur, and at this stage a definite neuritis begins, owing to malnutrition and the action of toxic substances.

Thereupon the patient usually manages to improve his environment. He takes off his boots and perhaps rubs his feet. Owing to the removal of the pressure of his boots, or owing to the restoration of the blood circulation, lymph pours out into the surrounding tissues and the feet swell.

In the severer cases, when the swelling, if occurring, has subsided, the feet often remain flushed and secrete sweat abundantly, the result, probably, of disturbance in the function of the nerves supplying the blood vessels and sweat glands. At this stage there is well-marked anaes. thesia or hyperaesthesia and some loss of movement.

Bearing in mind that none of the three cases of the " third degree" showed hyperaesthesia, and that in only one of them did the anaesthesia spread beyond the area of gangrene, we suggest that in continued bloodlessness of a part of the foot the neuritis is much less pronounced than in a temporary interference which later passes away and allows of a freer diffusion of toxic products into the tissues. 
Certain cases already described establish a close rela. tion, if not a transition, between the neuritis thus arising ind that due to so-called "rheumatism." In this connexion the possible invasion of ultramicroscopic organisms may be worth consideration. A susceptibility certainly appears to be shown to the attaclis of micro-organisms, in particular to Staphylococcus albus.

On the other hand, in some cases the disturlbances of seasibility were complicated by the general mental conclition of the pafient. Nevertheless, that they are to be regarcled as primarily the result of -a local "organic" neuritis vather than of a central "functional" dissociation, we liave not the slightest doubt.

Of the 152 men admitted, belonging to twenty-two ilifiercnt regiments, more than a third ( 37.5 per cent.) came from two regiments, both of which had just returned from Iudia. Of the remainder more than a third (41 per ccnt.) came from three other regiments, of which two are known to have been sent to the seat of war from Egypt and Malta. It is therefore probable that want of recent idaptation to cold and wet may be a predisposing influence.

That the hallux should be the part of the foot which suffers most severely recalls its proneness to attacks of yout. Perhaps the blood circulation is more liable to obstruction in the hallux than in the other toes.

The notes of the cases have been taken by Captains S. $\mathbf{R}$. Scott, F.R.C̈.S., W. P. S. Branson, F.R.C.P., Harold Puitcli ard, M.R.C.P., C. S. Myers, M.D., 'T. M. Body, M.R.C.S., Lieutenant J. S. Burn, B.C., Messi's. I. 'I'. Giles, F.R.C.S., J. P. Hedley, F.R.C.S., H. R. Robinson, and If. S. Crichton Starkey, M.B. 'The Registrar's work was tacilitated through an initial aualysis by the last named. 'The photograph of the last. rase was taken by Jieutenant I) udley Stone, M.R.C.S., radiographer to the hospital.

$$
\text { Sireve Cascs. }
$$

The following are the notes the severe cases to which raterience is made earlier:

CAsk $\mathrm{x}$.-Necrosis of Shin.

Private R. F., admitted Novem ber 16th, 1914, had sustained a ind haemothorax. He was severely ill with the condition of lung and pleura. About three days after admission, when his leet "began to get warm," he noticed "pins and needles" and pains in both feet, worse in the right. It was then noticed that there was an area of skin on the sole of the right foot which uppeared to be bruised and which was anaesthetic. The skin on this area gradually necroser, and $\epsilon$ ventually sloughed off. l'reated by fomentations. There was no anaesthesia in the toes.

The history of his frost-bite was as follows. While in the tiench he was able to walk up and down, and so his feet never fot numb. After being hit he lay in the trench twelve hours, until bearers came and took him to the dressing station. Exposed in the open trench that night to hail and cold, he felt his feet becoming numb, and finally he lost all feeling in them. It the dressing station his stretcher happened to be in front of the fire, and consequently his boots and stockings steamed (he could not feel the heat of the fire). When his boots were seen to he steaming they were taken off, and a hot-water bottle was placed on his feet, but he could not feel it. He left the dressing station in the evening for the train journey to this hospital. He says that he could not feel his feet properly until fourteen days after admission.

$$
\text { CASE xr.-Necrosis of Skin. }
$$

Private R. C. was admitted on December 3rd, 1914. About ten days earlier he noticed that both his feet felt very hot. He left the trenches that night, and took off his boots when he got to his billet. Next morning he noticed that both his feet were much swollen, and he had much trouble in getting his boots on, and only succeeded by slitting them down either side of the iongue. He then ctirl another three days' duty in the trenches, and again returned to his billet for a night's rest. He went back for another four days in the trenches, but suffered severe pain in his feet. On his return from the trenches he did not take his boots off, as he had to appear in a review before the King. That night he was on sentry duty for three hours, and on the next day he did a day's digging. He was then told to march two miles to draw rations, which he was unable to do; he reported himself sick. He found a large swelling under the big toe of his right foot. At the hospital, while the surgeon was examining the ball of this big toe, the swelling burst, and the skin was then cut away. The patient thinks the skin cut away was " white with some blue about it."

On admission the right foot was anaesthetic from the tips of the toes to about midway between toes and heel. The toes of the left foot were numb, but not completely sumesthetic. There was hyperaesthesia on pressing the toes in both feet. On the was hyperaesthesia on pressing the toes in both feet. On the plantar aspect of the right foot there was a patch of gangrene
involving the entire thickness of the skin. The margin was red and inflamed.

One week later the gangrenous area was sharply defined and the island of skin black and dry; sensation over the remainder of the foot had returned. Hyperaesthesia on pressure was stil present, the left foot was practically normal. The right foot was painted with a solution of picric acid and spirit and covered with sterile gauze. It healed well.

$$
\text { CASE XII.-Ulceration. }
$$

Private A. D., when admitted on December 3rd, 1914, had an ulcer on the great toe of the right foot. The toe was com. pletely anaesthetic, but the remainder of the foot normal. Prior to the appearance of the ulcer the toe had been greatly swollen for sever
the trenches.

CASE XIIr.-Local Asphyxia Private of Skin.

Private C. A. S., two days prior to admission on Decembe Ilth, 1914, took off his boots and was unable to get them on again owing to swelling of the feet. On admission both feet were red and swollen up to the ankles, the right bein's worse than the left. Over the head of the fifth metatarsal of the right foot there was a patch of dark blue skin, and below tlu external malleolus there patch of bright red skin. was patch of bright red skin. Both hyperaesthetic.

CASE XIV.-Necrosis of Skin. Private W. B. was admitted on December 3rr, 1914. Five days previously he noticed that his right foot felt cold and sore There was not much pain in it nor did it swell much. On admission the skin over the terminal phalanx of the right hallux was found to be gangrenous a clear line of demarcation stivrounded the gangrenous area. The skin over the dorsal surface of the first phalanx of the hallux was red and swolien. At the root of the nail was a small collection of jus from which Staphylococcus albus was cultivated. The swelling and redness gradually disappeared after treatment by fomentations.

The patient never experienced any pain or hyperaesthesia. There was an area of tactile anaesthesia, which involved the right hallux; there was no anaesthesia, elsewhere, and no right hallux; the

\section{Case Xv.-Gangrene of Feet follouing Exposure in a German}

Private A D. (Geim

Private A. D. (German prisoner of war) was admitted on
November 17th, 1914. This case, although not arising through exposure in the trenches, is here added as an extreme example of frost-bite.

On November 3rd he was hit in the buttock and in the middle toe of the left foot, probably by German fire during an attack on British trenches. He fell and remained in wood for foul or five days with very little food and exposed to much rain anc cold (not frost). He cut off his boots on the second das an found that his feet were swollen and that he his no feeling them. Unable to walk, he gave himself up to British ing in whose attention he manas whe attention he managed to attract. On admission both feet were swollen, bluish-black, oedematous, cold, and insensi tive. There were many large blisters on them containing serous fluid. The oerlema extended to the junction of the upper and middle third of each leg; temperature 102.4,
palse 100. His general condition, usually frail, was now very weak.

November 28th. A line of demarcation had formed on eacl foot at the level of the ankle joint. The feet were very foulsmelling. Both feet were amputated at the junction of the upper and midale thirds of the tibiae; anterior and posterin 
flaps were made and the wounds closer by suture, except a small part posteriorly.

The note on December 10th was that he had made uninterrupted progress and that the wounds were clean and healthy, healing by first intention.

C in December 3lst the wounds were completely healed.

\section{EXTRACTION OF A SHRAPNEL BULLET FROM THE KNEE-JOINT THROUGH A VERTICAL INCISION. \\ By WILLIAM ROBINSON, M.S.Dunely., F.R.C.S.ENG., \\ SENIOR SCRGEON TO THE ROYAL INFIRMARY, STNDERLAND.}

Tre object of this short paper is to draw attention to the great advantages obtained by a long rertical incision in opening the knee-joint for the purpose of exploring it or for treating certain injuries of the joint. Other surgeons have written on this subject-for example, Ollicr, R. Jones and Alwyn Smith ${ }^{1}$ and Corner. ${ }^{2}$

One great advantage of this incision is that a full view of the joint is obtained, including the suprapatellar pouch, the crucial ligaments, both condyles, both semilunar cartilages, and the upper surface of the tibia, after dividing the ligamentum mucosum near its attachment to the intercoudyloid notch, and removing the infrapatellar fat. Then also the movements of the semilunar cartilages can be watched during rotation outwards and inwards of the leg and the method by which these cartilages may be caught between the bones whilst the leg is rotated out or in and torn by a sudden contraction of the strong extensor muscles of the thigh, which are inserted into the capsule of the joint, demonstrated, as was first pointed out in $\mathrm{my}$ paper on "Torn Semilunar Cartilages" in this Jocrsal of January 17th, 1914.

Other advantages of this incision are that none of the important structures which bind the bones together are divided

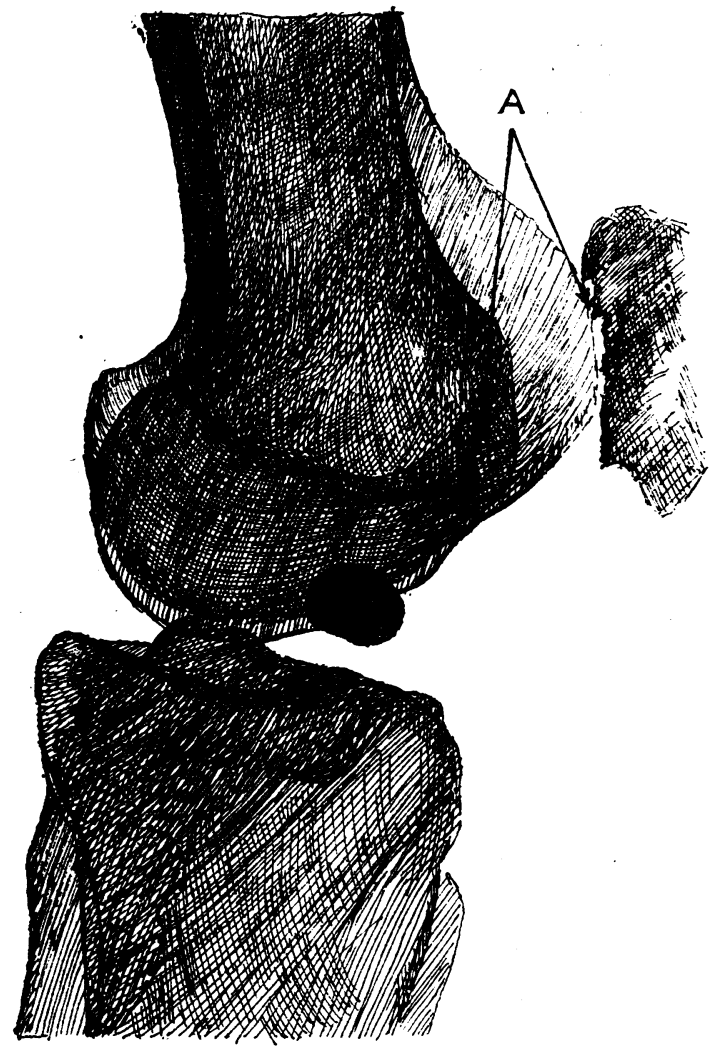

Fig. 1.-Shrapncl bullet in left knec-joint: lateral vicw. , Cartilages grazed by bullet.

transversely, therefore the divided parts tend to come together naturally, and after healing is complete the joint is in no way waturally,

A sergeant of the 2nd Manchesters mas mounded on October 13th last outside Bethune and was admitted a few days later into the Royal Infirmary, Sunderland. shrapnel bullet had penetrated the left linee-joint, the point of entry being one inch to the inner side and slightly abore the linee-cap. The joint was swollen for some

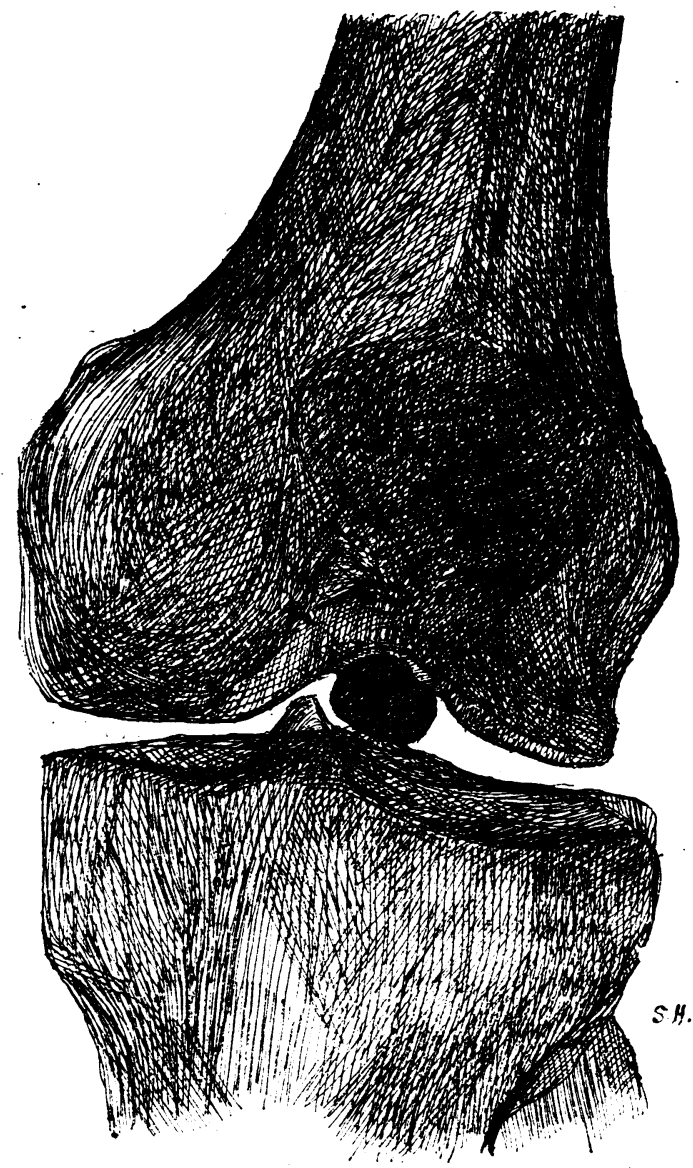

Fig. 2.-Shrapnel bullet in left knee-joint; front view.

wceks, and movements of extension and flexion were both painful and limited, even after the swelling had subsided and the small wound had healed. Stereoscopic radio. grams made by Dr. Squance and Dr. Hamilton Ross showed the bullet to be lying free in the joint in front of the anterior crucial ligament.

Operation.

On December 9th, assisted by Dr. Squance, I operated upon the joint. The patient was placed in the Trendelen burg position, and a vertical incision made through the skin, extending from 3 inches above the patella to the tubercle of the tibia, and the muscle, the periosteum of the patella, and its tendon were divided in the mid-line, whilst the joint was flexed. The loose fatty layer of connective tissue lying between the extensor muscle and the synovial pouch was dividerl and the latter also opened vertically. The cancellous tissue of the knee-cap was casily and rapidly sawn the gaw and strip of lead foil. B, Upper apart by two hooks and. the of incision: $v_{1}$, wound of apart by two hooks and the entrance.

joint exposed. The synorial

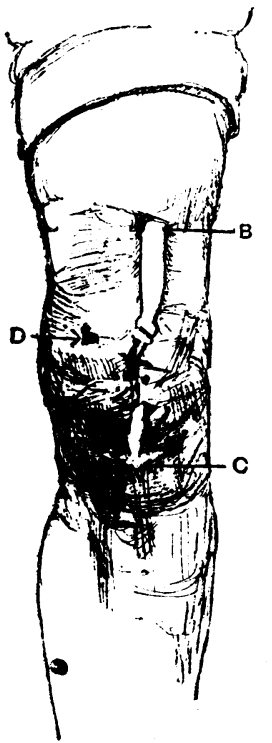

pouch above the linee-cap was practically obliterated by recent adhesions. The bullet was at once seen to be lying in the base of the ligamentum mucosum. 